\title{
Recuperando o objeto: extrapolações volumétricas de found footage ${ }^{1}$
}

\author{
Gabriel Menotti Gonring \\ https://orcid.org/0000-0002-7435-5539
}

I - UFES

Vitória (ES). Brasil

Resumo: Esse artigo examina, brevemente, a história e os pressupostos operacionais de formas de reconstrução volumétrica baseada na captura de dados visuais, em particular a fotogrametria digital. A fotogrametria é uma das principais técnicas empregadas atualmente na produção de réplicas virtuais de patrimônio para fins de conservação. O realismo computacional obtido com esse processo induz à crença de que seja possível recuperar a totalidade de um objeto a partir de seus vestígios midiáticos. Ao recorrer a projetos artísticos que evidenciam as idiossincrasias dos modelos gerados, pretendemos colocar em questão os limites dessa promessa tecnológica.

Palavras-chave: fotogrametria; found footage; hiperfidelidade computacional.

Abstract: Retrieving the object: found footage volumetric extrapolations - This paper briefly examines the history and the operational underpinnings of forms of volumetric reconstruction based on the capture of visual data, particularly photogrammetry. Photogrammetry is one of the chief techniques currently employed in the production of virtual replicas for heritage conservation. The computational realism resulting from this process induces us to believe that it is possible to recover the totality of an object from its media traces. We mean to challenge this technological promise by referring to artistic projects that explore the idiosyncrasies of photogrammetric models.

Keywords: photogrammetry; found footage; computational hyper-fidelity.

\section{Introdução}

Entre 2008 e 2012, um grupo de pesquisa do departamento de Ciência da Computação da Universidade de Cornell, com o apoio de tech giants como a Amazon e a Microsoft,

1 Pesquisa realizada com suporte da Comissão Fulbright e apresentada originalmente durante o XVIII Encontro Anual da Compós. 
dedicou-se a um projeto que apelidou de BigSFM: um nome aparentemente trivial para descrever o ousado propósito de "reconstruir o mundo a partir de fotografias encontradas da Internet". No registro da National Science Foundation norte-americana, a pesquisa consta como RI-Small: Multi-level Priors for Multi-view Stereo. Fundamentalmente, seu trabalho pretendia avançar sobre as possibilidades de produção de um modelo tridimensional fidedigno de toda a Terra com base no processamento computacional de dados extraídos a partir de bancos de imagem on-line.

A página do projeto na web reúne alguns resultados intermediários que apontam para esse objetivo, entre eles estão os links para os algoritmos desenvolvidos, os modelos de cidades realizados (Dubrovnik, Roma e Veneza) e os papers publicados desde 2009. O mais antigo deles, sob o título "Construindo Roma em um Dia" [Building Rome in a Day], descreve os desafios envolvidos na produção de um conjunto de 16 milhões de pontos geométricos correspondentes à capital italiana. Esse modelo representa dezenas de seus principais pontos turísticos. Foi resultado do cruzamento de 150 mil fotografias da cidade encontradas na plataforma Flickr, que, a época, tratava-se do principal canal on-line para publicação e compartilhamento de imagens. Para tanto, foram empregados 496 núcleos computacionais num processo que durou cerca de 21 horas (AGARWAL et al, 2009).

A despeito de seu caráter eminentemente contemporâneo, salientado pela aplicação de alta tecnologia, há, no BigSFM, uma forte expressão do mesmo paradigma indiciário que, conforme demonstrou Carlo Ginzburg (2013), fundamenta importantes aspectos da cultura ocidental desde o final do século XIX. Trata-se de um modelo de conhecimento que reverbera nossos antepassados caçadores e coletores que busca recuperar a totalidade do objeto a partir de seus rastros. Ginzburg aponta como a noção indicial de verdade marcou a consolidação das ciências modernas, desde a análise filológica da obra de arte e a criminologia forense até a medicina e as disciplinas conjecturais. A fotografia, como um meio de representação calcado na indicialidade, assume um papel central nas operações de detecção própria desses campos.

Como ressalta Tom Gunning (1995, p. 20), a fotografia apresenta-se como uma ferramenta ideal de reconhecimento não apenas porque se constitui a partir de uma impressão material do objeto representado, mas também por causa da semelhança que guarda para com ele. Com a representação fotográfica, a manifestação simultaneamente física e mimética do objeto isenta-se da contiguidade espaço-temporal, ganhando, dessa forma, autonomia. A natureza destacável do fotograma serve como um potente tratamento discursivo da realidade. Ela nos permite inscrever a aparência do objeto em sistemas de troca e classificação dissociados da sua presença e, assim, fixa a sua identidade enquanto entidade singular e coesa. Não se trata de um mero apagamento do corpo mas, pelo contrário, trata-se do seu desdobramento em "imagens transportáveis, completamente adaptadas aos sistemas de circulação e mobilidade que a modernidade demanda" (ibidem, p. 18).

Ao viabilizar essas operações, a fotografia se tornaria um elemento constituinte dos discursos de poder e controle que emergeriam a partir de meados do século XIX. Jonathan 
Crary a reconhece como um "componente crucial de uma nova economia cultural de valorização e troca" então estabelecida. Como o dinheiro, a fotografia "produz um novo conjunto de relações abstratas entre os indivíduos e as coisas e impõem essas relações como o real" (1990, p. 13). Seu uso é particularmente marcante no âmbito jurídico, sobretudo quando a objetividade da evidência material ganha precedência sobre o depoimento de testemunhas. Similarmente, a fotografia será empregada em novas formas de policiamento e, almejando certa precisão científica, privilegia a detecção atenta sobre a força bruta. Gunning destaca, por exemplo, a padronização dos expedientes de captura e a criação de coleções de fotografias de criminosos como formas de viabilizar a identificação da população em grandes cidades europeias (GUNNING, 1995, p. 23-4).

A iniciativa da Universidade de Cornell indica, já em seu nome, o intuito de atualizar esse impulso moderno por meio do paradigma do big data, visto que esse envolve a captura, armazenagem e análise computacional de conjuntos massivos de dados. Atualmente, as principais aplicações dessa metodologia se dão no estudo de sistemas complexos tais como no comportamento de redes de usuários nas Internet e nos efeitos das mudanças climáticas nos ecossistemas terrestres. No BigSFM, a capacidade do big data em realizar modelos preditivos minuciosos combina-se ao projeto de recuperar o mundo a partir de seus rastros na promessa de um governo completo sobre o tempo e o espaço por meio da computação. É como se pudéssemos, a partir das evidências disponíveis, projetar tanto o futuro quanto o passado em alta fidelidade.

\section{O procedimento de síntese volumétrica por fotogrametria}

A realidade desse domínio sobre o tempo e o espaço precisa, entretanto, ser examinada à luz das técnicas de reconstrução empregadas. Com esse intuito, voltamo-nos para a outra parte do nome do projeto: a enigmática sigla SFM. Ela se refere à structure from motion [estrutura baseada no movimento], termo que designa sistemas e processos capazes de recriar um volume tri-dimensional a partir de uma sequência contínua de imagens bi-dimensionais. Esses sistemas constituem um caso particular de fotogrametria, que, por sua vez, compreende todo um conjunto de técnicas de medição baseadas no uso da fotografia. A fotogrametria existe há mais de um século. Suas primeiras aplicações se deram nos campos da arquitetura e da topografia. Mais recentemente, ela tem ganhado destaque e servido como base para a produção computadorizada de modelos 3-D realistas, e, a partir daí, tem-se difundido por outras áreas.

A fotogrametria opera a partir de fundamentos geométricos e da crença na precisão óptica. A fidelidade inerente à projeção perspectiva produzida pela câmera garante que possamos aferir, com precisão, as dimensões do espaço retratado, contanto é preciso

que saibamos alguns de seus parâmetros de captura e/ou representação. É possível e até relativamente banal, determinar a distância relativa entre pontos que estejam situados 
em um mesmo plano paralelo ao plano de projeção da imagem. A partir da combinação de duas ou mais fotografias realizadas por meio de diferentes perspectivas, de modo que os seus planos de projeção se sobreponham adequadamente, é possível determinar a distância exata entre esses pontos e o oculus. Este, por sua vez, corresponde à localização da câmera no momento de tomada da imagem.

Com isso, conseguimos obter as coordenadas do conjunto de pontos em um sistema cartesiano tri-dimensional e, a partir daí, restituir a volumetria dos elementos representados. Cientes da escala visual empregada ou mesmo do tamanho original de algum desses elementos, podemos traduzir as medidas do modelo nas medidas reais do espaço representado. Os cálculos geométricos por trás dessas técnicas são mais antigos do que a própria fotografia e as suas primeiras aplicações se deram logo após a invenção do Daguerreótipo. Já em 1859, o coronel Aimé Laussedat, do corpo de engenheiros do exército francês, havia demonstrado sua aplicabilidade para o mapeamento topográfico com o uso de instrumentos terrestres (OLAGUE, 2016, p. 21). Nas décadas seguintes, com o desenvolvimento da fotografia aérea, a fotogrametria se consolidaria com uma importante ferramenta para a cartografia de precisão.

Durante a primeira Guerra Mundial, ela foi amplamente utilizada para o reconhecimento de terreno por ambos os lados do conflito. Granshaw (2015, p. 331) aponta a sofisticação da tecnologia alemã à época, encabeçada por companhias como a Zeiss, que também fabricava equipamentos para restituição fotogramétrica e câmeras especializadas tais como periscópios binoculares. Nessas ocasiões, a fotogrametria ainda não era empregada para a produção de modelos tri-dimensionais, mas sim para retificar as distorções ocasionadas no plano cartográfico pela perspectiva de captura. O processo, essencialmente manual, utilizava equipamentos estereográficos e esses, por sua vez, faziam pares de fotografias sobrepostas coincidirem numa prancha de plotagem, corrigindo, assim, as suas discrepâncias de angulação por meio de um sistema óptico, de modo a combiná-las numa projeção ortogonal (sem pontos de fuga).

Essa projeção permitia representar, com precisão, a distância entre os elementos mapeados e o traçado das curvas de nível topográficas. O desenvolvimento de sistemas de SFM se deve à abstração desses mecanismos em rigorosas fórmulas matemáticas, que possibilitariam a sua posterior computadorização. A chamada fotogrametria analítica se aprimorou a partir de uma abordagem iterativa para a determinação de posições de câmera inventada na década de 1930 por Earl Church, professor de matemática aplicada da Universidade de Syracuse (DOYLE, 1964, p. 260). Tendo noção dos parâmetros de tomada fotográfica, sejam eles conhecidos de antemão ou inferidos por meio de cálculos é possível empregar algoritmos de multivisão estéreo [MVS - multi-view stereo] para efetuar uma reconstrução densa do objeto retratado por meio de um conjunto com qualquer número de imagens (FURUKAWA \& HERNÁNDEZ, 2013, p. 14).

Quanto mais informação visual disponível, mais fiel a volumetria produzida será. Nas últimas décadas do século XX, o desenvolvimento de software capaz de automatizar 
as operações envolvidas nesses cálculos projetivos (ver por exemplo LONGUET-HIGGINS, 1981; STENSTROM \& CONNOLLY, 1992) aliado à digitalização dos dados visuais que lhes servem de base (na forma de imagens raster, constituídas por matrizes de pixels), levam à incorporação da fotogrametria ao conjunto de recursos disponíveis para o campo da visão computacional. Particularmente, a fotogrametria virá a ser aplicada na detecção de profundidade [depth sensing], e, assim, permite o reconhecimento maquínico da terceira dimensão do espaço. A triangulação de padrões de pixels coincidentes, por conseguinte, gera uma nuvem de pontos tri-dimensional [point cloud] que pode servir de base para processos de extração de características, reconhecimento de objetos e até mesmo para a interpretação simbólica dos elementos retratados.

O lançamento de pacotes comerciais como Photoscan (Agisoft, 2010) e Reality Capture (Capturing Reality, 2016) estabeleceu a fotogrametria como uma solução para a digitalização de volumes amplamente empregada no escaneamento 3-D de estruturas e terrenos. Esses programas são capazes de produzir, a partir da nuvem de pontos obtida com algoritmos de SFM-MVS, uma malha poligonal [mesh] do objeto escaneado. Por meio da projeção das fotografias originais sobre essa malha, usa-se, como referência, as posições relativas de tomada de imagem. Também pode ser gerado um arquivo de textura de alta resolução. Combinadas, essas operações visam resultar em um modelo 3-D virtual visual e volumetricamente consistente com o seu referente.

A versatilidade da fotogrametria digital como método de escaneamento 3-D estendeu o seu uso para outras disciplinas além das geociências tais como a arquitetura e a arqueologia. Atualmente, trata-se de uma das principais soluções empregadas no registro do patrimônio para fins de conservação e promoção. O Instituto Smithsonian e o Museu Britânico estão entre as instituições que digitalizaram peças de suas coleções e disponibilizaram réplicas virtuais na Internet para apreciação do público. O modelo digital documenta a volumetria e aparência do objeto de um modo que a simples representação bidimensional (como uma fotografia) nunca poderia fazer. Dessa forma, conta com a vantagem adicional de poder ser manipulado, inserido numa variedade de contextos reais ou simulados e até impresso em 3D. Gera-se, então, uma cópia que pode servir para fins pedagógicos específicos (tal como o acesso de deficientes visuais à obra).

Devido ao seu alto nível de detalhamento, a réplica virtual pode se tornar uma interface para a análise do patrimônio, dispensando, assim, o contato físico salvo nos casos mais extraordinários, contribuindo, dessa forma, para a sua preservação. A eficiência da fotogrametria para a produção de modelos virtuais chegou a determinar a sua adoção pela indústria do entretenimento. Destaca-se por atuar como um processo de baixo-custo para geração de elementos virtuais verossímeis para filmes, videogames e ambientes de realidade virtual. Recentemente, por exemplo, a fotogrametria foi utilizada para a composição de cenários para o longa Mad Max: Fury Road (Warner Bros, 2015) (FAILES, 2015). A meio caminho entre esses diversos campos, encontramos aquela que talvez seja a realização mais completa dos sonhos do BigSFM: o Google Earth. 
O simulacro planetário da Google, formado pela combinação de dezenas de milhões de fotografias da Terra, em múltiplas camadas de aproximação, também apresenta modelos 3-D de diversas cidades e formações topográficas. Todos esses modelos são gerados, automaticamente, por meio de processamento fotogramétrico. Diferente daqueles produzidos no projeto da Universidade de Cornel, eles não se baseiam em conjuntos de imagens encontradas. A Google lança mão de uma equipe própria para fazer a varredura de seus pontos de interesse geográficos, empregando, para tanto, um aeroplano equipado com cinco câmeras e sistemas de GPS (NAT \& FRIENDS, 2017). Com isso, a empresa busca controlar as condições de captura e a correspondência entre as imagens produzidas, de modo a garantir a calibração e a máxima fidelidade dos modelos finais.

Experimentar o Google Earth em realidade virtual, pelo aplicativo que a própria Google lançou no final de 2016, é uma experiência bastante educativa para aprender sobre os limites da fotogrametria. Passado o arrebatamento inicial,, os modelos vão, aos poucos, revelando suas imperfeições. A possibilidade de examiná-los, por diversos ângulos, com visores estereoscópicos, nos permite detectar uma série de incongruências volumétricas que a planificação do monitor ou esconde ou suaviza. Essas deformidades ficam ainda mais aparentes nos breves vislumbres que temos das malhas poligonais "nuas", antes que suas texturas tenham sido completamente carregadas na memória da máquina. Não é que se tratem de modelos fajutos. Pelo contrário, são incrivelmente plausíveis dentro das circunstâncias em que nos são apresentados. Espantosos, até. Mas a sua correspondência ao real não pode ser exagerada. As geometrias que o Google Earth apresenta como uma reprodução fiel da Terra, ainda que sejam geradas a partir de seus indícios fotográficos, nitidamente não condizem com as formas perceptíveis do planeta.

\section{Recriações do real, suas lacunas e eclosões}

As inconspícuas deficiências do Google Earth nos atentam para o fato de que os usos da fotogrametria como ferramenta de captura do real são indissociáveis de seu emprego na criação de imagens. Em suas primeiras aplicações cartográficas, a fotogrametria servia não apenas para obter uma certa verdade pós-indexical do território, que não poderia ter sido capturada por nenhuma câmera, servia, também, para fabricar um modo de representar visualmente essa verdade. Nesse sentido, a técnica já buscava avançar na substituição do realismo fotográfico, subordinado-se ao aparelho ocular humano pelo hiperrealismo computacional, baseando-se, para tanto, em abstrações matemáticas. Em suas mais recentes aplicações no campo da produção audiovisual, por outro lado, parece ocorrer o contrário. A fotogrametria é empregada menos para obtenção das exatas medidas do real do que dos seus efeitos sensórios.

Aqui, como também detectou Crary no caso das primeiras estereoscopias, o realismo não é inerente à imagem capturada, mas sim um produto do seu rearranjo tecnológico em acordo com a experiência do observador (1990, p. 120-2). Essa busca pela verossimilhança midiática frequentemente demanda o sacrifício da fidelidade volumétrica dos modelos 
obtidos. Ao fim do processo de escaneamento, uma malha poligonal pode compreender centenas de milhares de faces, o que a torna pesada e dificulta a sua manipulação em aplicativos de modelagem e composição 3-D. Por meio de operações de remalhagem [remeshing] e dizimação [decimation], o modelo precisa ser reorganizado e simplificado de modo a otimizar o seu uso em outras aplicações. O que afinal preserva a sua aparente fidelidade ao referente é o revestimento dado pela textura fotográfica: uma imagem bitmap construída como um mosaico a partir das fotografias que lhe servem de base, mapeadas, contudo, de acordo com a topografia poligonal da malha.

Nesse caso, o processo de reconstrução volumétrica parece visar, antes de uma reprodução do real, a sua recriação instrumental, perfeitamente adequada a determinado contexto de execução. A reivindicação de uma correspondência plena entre modelo e objeto, ainda que conjectural, depende de que acreditemos que as triagens realizadas nesse sentido operem a favor, e não contra, a transparência e neutralidade da sua reconstrução. Não seriam, portanto, aditivos nem disfarces, e, assim, não eram responsáveis por promover a falsificação do real, mas sim se ocupavam em elaborar filtros capazes de eliminar ruídos, depurar algo a mais da sua essência e, por meio da modulação de informações, nos aproximar da sua representação mais fidedigna.

Essa premissa é colocada à prova por trabalhos artísticos que, abraçando o espírito do ready made, empregam a reconstrução volumétrica como forma de promover o deslocamento de representações visuais de um sistema de mediação tecnológica para outro. Esses trabalhos tomam vídeos ou outros conjuntos de imagens encontrados na Internet, muitos das quais altamente comprimidos ou de baixa nitidez e os utilizam como base para o processo de reconstrução espacial estéreo. Levada a operar sobre um material que não foi adequadamente preparado, a fotogrametria atinge os seus limites de funcionamento. Nos óbvios desajustes entre os modelos resultantes e seu suposto referente duplamente removido, os algoritmos de SFM-MVS demonstram contundentes interferências generativas sobre os processos de mediação do real.

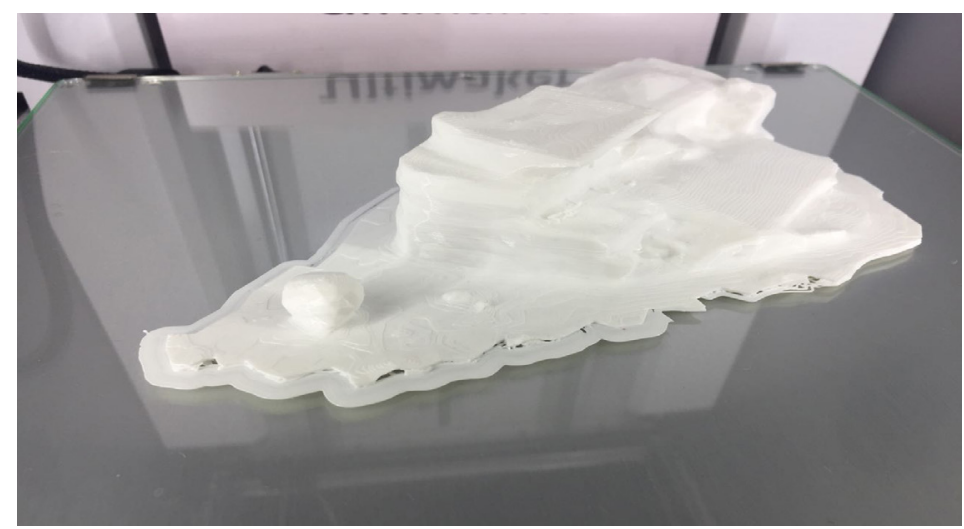

Fig. 1. Impressão 3-D do modelo Phantasm em plástico.

Fonte: Tom Burtonwood. 
Em Phantasm (2017), por exemplo, Tom Burtonwood parte de uma sutil "engenharia reversa" do Google Earth para comentar sobre a condição de simulacro da plataforma. O trabalho foi preparado para uma exposição de objetos impressos em 3-D realizada na Galeria Transitória da Red Bull Station, em São Paulo. Por meio da captura em vídeo da tela do programa, o artista obteve um conjunto de vistas que o permitiram extrair o modelo de baixa resolução [low poly] com que o prédio da Red Bull Station é representado no sistema da Google. Impresso em plástico monocromático, sem a textura fotorrealista para mascarar as suas deformidades, o modelo aparece como uma maquete bastante imprecisa. A distância entre o real que ele materializa e a forma que ele representa é destacada pela sua aproximação com o referente na situação de exposição.

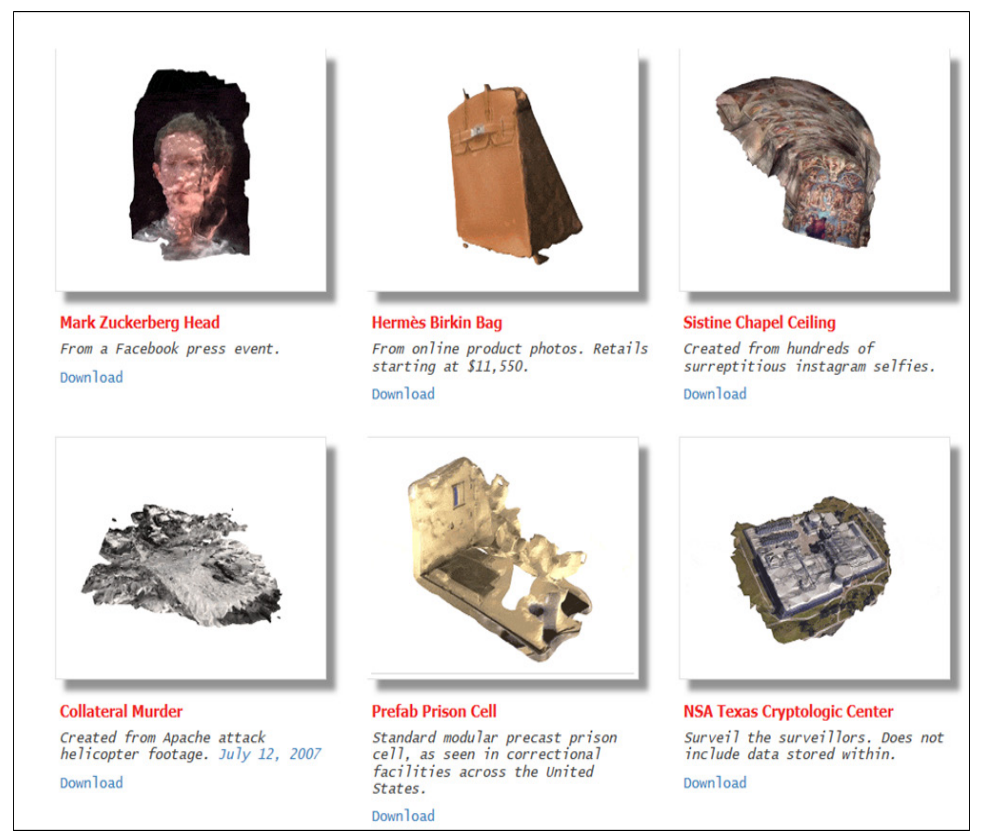

Fig.2. alguns dos modelos disponíveis no site Contrascanned. Fonte: Zak Ziebel

Já modelos como os da escultura Vitória da Samotrácia e do teto da Capela Sistina realizados por Zak Ziebel para a sua série Contrascanned (2016) nos levam a reconsiderar, criticamente, nossas ambições de virtualização total do espaço. Contrascanned se apresenta como um pequeno acervo "clandestino" de objetos virtuais. Assim como no projeto BigSFM, a maior parte dos modelos foi gerada por Ziebel a partir de um processo de mineração de dados calcado na extração massiva de imagens a partir das contas de diversos usuários do Instagram. A principal diferença está na formalização final dos resultados. Enquanto os pesquisadores da Universidade de Cornell restringiram a representação de 
seus modelos às nuvens de pontos, ressaltando a precisão da reconstrução digital, o artista optou pela produção de malhas texturizadas.

Esse formato de saída não apenas torna impossível disfarçar as insuficiências das fontes de imagem empregadas, como também potencializa a proliferação de ruídos e deformações no processo de reconstrução. Com isso, no lugar de uma estética da desmaterialização, temos uma estética do derretimento, como se a malha poligonal não fosse capaz de conter o objeto que representa. A opção por obras renomadas, de grande apelo turístico e cultural, assegurou a coleta de um volume de dados suficiente para a realização de modelos mais ou menos completos e reconhecíveis. Não obstante, a inconstância dos conjuntos de imagens parece ter impedido que elas fossem organizadas em total coerência umas com as outras e, portanto, com os seus referentes.

A divergência entre as fontes parece suscitar os algoritmos de SFM-MVS a interpretar artefatos de compressão e aberrações cromáticas como formas a serem reconstruídas. Esse suposto "engano" da máquina ocasiona, às reproduções tri-dimensionais, além de desconcertantes lacunas, a manifestação de volumes-fantasma e de componentes que não deveriam estar lá. Ainda que o artista busque capitalizar sobre a clandestinidade do ato, apresentando a fotogrametria como uma forma de apropriação transgressora (um suposto "roubo") do objeto, parece mais interessante entendê-la como um bootleg: uma reprodução que é mais fecunda e não reprisa o real, mas justamente diverge, substancialmente, dele, afirmando, para tanto, as realidades do próprio processo de captura na forma reproduzida.

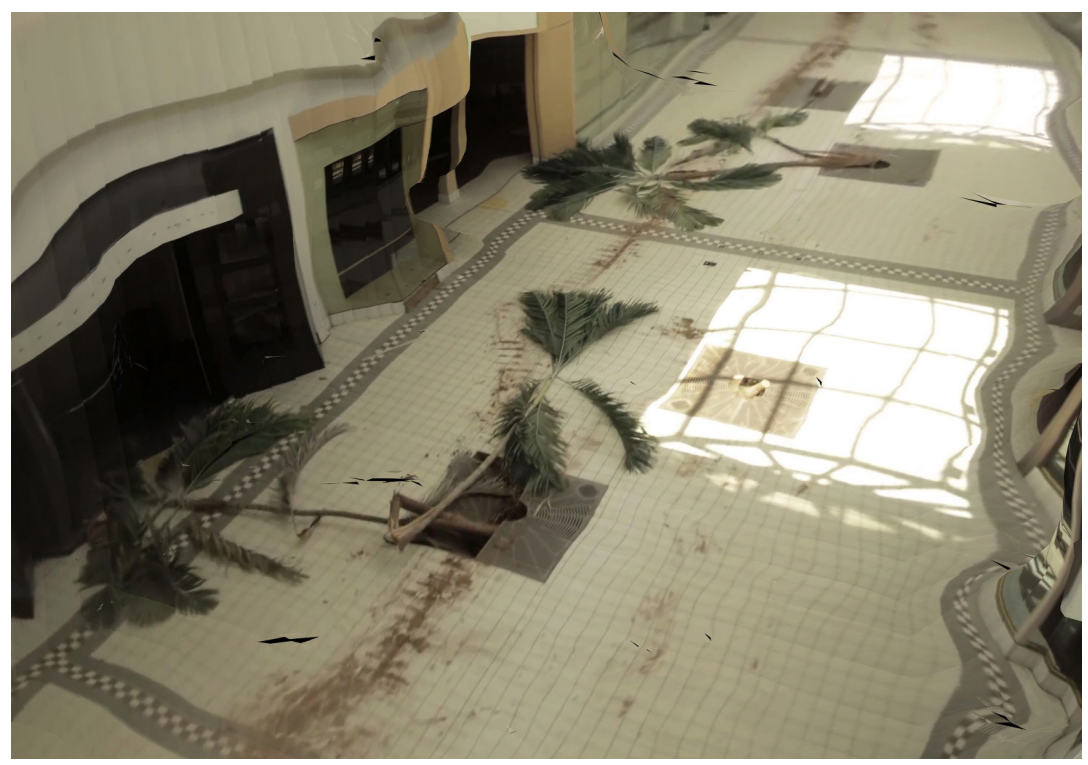

Fig. 3. Vista limitada de Merch Mulch (still). Fonte: Claire Hentschker 
Todavia, tampouco a obstinação da captura exime o simulacro de fraturas. A tenacidade humana em cristalizar o real é, novamente, confrontada pela insuficiência de suas ferramentas nos vídeos Catacombs (2016) e Merch Mulch (2017), de Claire Hentschker. Esses trabalhos levam o espectador para um passeio de $360^{\circ}$ pelo interior de shopping centers abandonados nos Estados Unidos, também reconstruídos em 3-D a partir de vídeos encontrados na Internet. Nesse caso, entretanto, não se tratam de conjuntos de imagens combinadas a esmo. O material original, exemplificado pela série Dead Malls, realizada desde 2015 pelo documentarista norte-americano Dan Bell, é fruto da exploração apaixonada desses lugares por cineastas amadores. São vídeos de alta resolução, feitos com esmero, e, particularmente, apropriados para a reconstrução volumétrica porque empregam planos-sequência que cobrem determinadas extensões do espaço por completo bem como em condições de captura homogêneas.

O entusiasmo do diretor com o seu objeto, frequentemente, traduz-se em um olhar curioso, atento aos detalhes. Tomando por base um material tão oportuno, as renderizações estereoscópicas de Hentschker, apresentadas em resolução 4k, paradoxalmente, frustram uma audiência que espera se encontrar imersa no passado. O problema decorre, primeiramente, do fato que a arquitetura de shopping centers emprega materiais reflexivos com os quais a fotogrametria tem dificuldade de lidar.

Vitrines, armações de aço polido e pisos de mármore encerado apresentam superfícies que "confundem" os algoritmos de SFM-MVS, sobretudo ao deslocar a posição da luz de um ponto ao outro por meio da tomada de imagem. A reconstrução do espaço fica, portanto, sujeita a interpolações extraordinárias que devem preencher o modelo com uma quantidade pressuposta de ruído geométrico e visual de modo a consolidá-lo. A capacidade de olhar ao redor no vídeo $360^{\circ}$, encarando um "verso" da imagem que, de outra forma, ficaria escondida, faz multiplicar as chances do espectador se encontrar com essas distorções. Na constante iminência de seu desmembramento, a reprodução dessas ruínas precoces parece exprimir o caráter irrecuperável do tempo.

\section{Considerações finais}

Os procedimentos indiciários que animam projetos como BigSFM e o Google Earth vão ao encontro do impulsionamento da totalização computacional da realidade. Calcando a sintetização digital do espaço e dos objetos em seus vestígios materiais, interpretados com automatismo e precisão, o uso de algoritmos SFM-MVS legitima a sua autenticidade. Os modelos 3-D resultantes se apresentam como produto da convergência entre a pretensa objetividade da captura fotográfica e a alta capacidade especulativa da simulação estatística. Essa combinação imbuiria a imagem de uma autoridade sem precedentes, admitindo, então, um alinhamento definitivo da História ao arquivo. Com seu extraordinário poder de imitação, a réplica virtual parece se colocar para além do tempo, nos capacitando a, simultaneamente, recuperar o passado e administrar o futuro. 
Não obstante, um olhar mais atento - seja aos modelos, seja aos processos que os constituem - revela os limites dessa competência mimética e da autoridade historiográfica por ela outorgada. Percebe-se que não há nada de completamente objetivo na técnica de reconstrução volumétrica por fotogrametria. A produção de uma identidade entre o modelo e o real depende, em primeiro lugar, de uma negação a priori das diferenças que constituem o próprio real. Os vestígios precisam ser selecionados e preparados de modo a suprimir do processo de virtualização as particularidades materiais com que ele não é capaz de lidar. Há, em segundo lugar, uma sistematização dos dados capturados, no sentido de adequar o modelo 3-D aos modos de percepção e engajamento a que ele se destina.

Essa etapa se presta não apenas à compensação de deficiências operacionais (ópticas ou algorítmicas) inerentes à anterior. Ela, de igual maneira, promove a negação da geometria real do objeto em prol da eficiência sensorial de sua réplica. Recusando esses expedientes de pré- e pós-produção, trabalhos como os de Burtonwood, Ziebel e Hentschker evidenciam a arbitrariedade da reconstrução volumétrica e, dessa forma, refutam a atualidade de seu controle. Como legítimos exemplares do que Jacques Rancière chamou de regime estético das artes, esses se contrapõem a uma hierarquia representativa baseada na imitação (2004, p. 21-2). Na sua apropriação de found footage, a suposta objetividade da linguagem (e a correspondente transparência entre processos de captura e representação) se mostra comprometida com a subjetividade da máquina.

Os modelos produzidos, ainda que não apresentem a alta fidelidade esperada de uma "boa" reprodução, constituem, não obstante, demonstrações de uma certa espécie de hiperfidelidade computacional. Significam, mais que o espírito das coisas, a expressão ectoplásmica de um certo além. Se por um lado divergem da realidade do objeto que buscam representar, por outro, exprimem, de maneira irrevogável, a realidade dos processos envolvidos nessa representação, incluindo as eventuais deficiências da base de dados, viéses algorítmicos e idiossincrasias operacionais. Em sua afirmação de opacidade, eles nos convidam a substituir, no horizonte da imagem em rede, a totalidade hiperreal por uma multiplicidade anamórfica, e, assim, quanto mais busca conter o objeto, mais se deforma e o extrapola.

Gabriel Menotti Gonring é professor de Edição e Multimídia na Universidade Federal do Espírito Santo, crítico e curador. É doutor em Media and Communications por Goldsmiths (Universidade de Londres) e em Comunicação e Semiótica pela PUC-SP. Apresentou trabalhos em eventos como o 160 ISEA, a 29a Bienal de São Paulo e o Festival Transmediale. Suas obras mais recentes são Movie Circuits: Curatorial Approaches to Cinema Technology (Universidade de Amsterdam, 2019) e a coletânea Curadoria, cinema e outros modos de dar a ver (Edufes, 2018).

gabriel.menotti@gmail.com 


\section{Referências}

AGARWAL, S. et al. Building Rome in a Day. Artigo apresentado na 12a Internacional Conference on Computer Vision, Kyoto, 2009.

CRARY, J. Techniques of the Observer: On vision and modernity in the nineteenth century. EUA: MIT Press, 1990.

DOYLE, F. The historical development of analytical photogrammetry. Photogrammetric Engineering, v. 30, n. 2, p. 259-265, 1964.

FAILES, I. A graphic tale: the visual effects of Mad Max: Fury Road. 29/05/2015. Disponível em: https://www.fxguide.com/featured/a-graphic-tale-the-visual-effects-of-mad-max-fury-road. Acesso em: 16/12/2018.

FURUKAWA, Y; HERNÁNDEZ, C. Multi-View Stereo: A Tutorial. Foundations and Trends in Computer Graphics and Vision, v. 9, n. 1-2, p. 1-148, 2013.

GINZBURG, C. Clues: Roots of a Scientific Paradigm. Clues, Myths, and the Historical Method. EUA: Johns Hopkins University, 2013.

GRANSHAW, S. I. Editorial - First World War Aerial Photography: 1915. The Photogrammetric Record, v. 30, n. 152, p. 330-338, 2015.

GUNNING, T. Tracing the Individual Body: Photography, Detectives, and Early Cinema. Cinema and the Invention of Modern Life. Ed. Leo Charney e Vanessa R. Schwartz. EUA: University of California Press, 1995.

LONGUET-HIGGINS, H. A computer algorithm for reconstructing a scene from two projections. Nature, v. 293, n. 10, p. 133-135, 1981.

NAT AND FRIENDS. Google Earth's Incredible 3D Imagery: Explained. Youtube. 18/04/2017. Disponível em: https://youtube.com/watch?v=suo_aUTUpps. Acesso em: 16/12/2018.

OLAGUE, G. Evolutionary Computer Vision: The First Footprints. EUA: Springer, 2016.

RANCIÈRE, J. The Politics of Aesthetics: The Distribution of the Sensible. Londres: Continuum International, 2004.

STENSTROM, J. R; CONNOLY, C.I. Constructing object models from multiple images. International Journal of Computer Vision, v. 9, p. 185-212, 1992. 